\title{
REVIEW ON BLENDED CONCRETES
}

\author{
G. Sree Lakshmi Devi ${ }^{1}$, P. Srinivasa Rao ${ }^{2}$, Srikanth Devi ${ }^{3}$ \\ ${ }^{1}$ Research Scholar, JNT University Hyderabad, Kukatpally, Hyderabad 500085.India \\ ${ }^{2}$ Professor, JNT University Hyderabad, Kukatpally, Hyderabad 500085.India \\ ${ }^{3}$ Assistant Professor, MREC, Hyderabad, India
}

\begin{abstract}
The paper presents the studies on properties of blended concretes containing various mineral admixtuers like fly ash, silica fume, ground granulated blast furnace slag and metakaolin as partial replacement to cement. By addition of these admixtures reduces the cement content so that it can minimize the enivornment impact from the producion of cement.Various properties of blended concretes are reviewed from different research articles.
\end{abstract}

Keywords- Blended Concrete, Binary Blended, Triple Blended, Quaternary Blended Concretes, Strength Properties, Durability Properties

\section{INTRODUCTION}

Extensively used material for construction is concrete all over the world. Concrete can generally be produced of locally available constituents, it can be cast into wide variety of structural configurations, and requires minimal maintenance during service. It is attractive in many applications because it offers considerable strength at a relatively low cost. To get the high strength for concrete by reducing the water content can achieve by adding the chemical admixture like water reducing agents to concrete. In some cases high strength requirement is not sufficient even other properties also to be enhanced like durability, low permeability and good workability. For this purpose pozzolanic materials are incorporating in to concrete like fly ash , silica, ggbs..etc those are called as mineral admixtures. Incorporation of these admixture not only enhance the properties of concrete they also reduces the cement content in concrete. The reduction of cement content means it minimise the environment impacts caused in cement production process and most of these materials are industrial by-products, problems with disposal also can be solved.

Admixture are added to batch immediately or during mixing to modify one or more of the properties of concrete in fresh and hardened state. the use of mineral admixture as partial replacement to cement in concrete is common practice in modern concrete technology. in this literature reviewed the effects of mineral admixtures on concrete properties in different forms like binary, ternary and quaternary blends. the effects like workability, strength development, resistance to alkali-aggregate reactions and sulphate attacks etc.

\subsection{Mineral Admixtures}

Some of these admixture properties and sources are briefly described as follows.

\subsubsection{Fly Ash}

It is a by-product from thermal power plants and it is most available supplementary Cementitious material (SCM)'s in the world approximately 600 Million tonnes. It indicates potential for the use of larger amounts of Fly ash in concrete but at early ages of concrete containing high volume FA effect the properties of concrete like strength development and lower durability performance. Coming to about fly ash it composed of silica, alumina and iron having average particle size of around 35 microns in glassy and spherical shapes. Different researchers made study on fineness of fly ash effect on concrete and it was concluded that as fineness of fly ash increases compressive strength of concrete increases. When fly ash incorporation in concrete it reduces the heat of hydration, increases the fluidity of concrete. In the presence of moisture fly ash gives meta-stable alumino-sillcates that react with calcium ions, this reaction forms silica hydrates.

\subsubsection{Silica Fume}

It is by-product in the production of metallic silicon or ferrosilicon alloys composed of submicron particles of $\mathrm{SiO}_{2}$. Norwegain researchers were first utilization of Silica fume in concrete in 1952.SF particle size much smaller than OPC of about 0.1 to 0.2 microns. Yearly silica fume production is there about 1 to 1.5 million tonnes per year throughout worldwide $^{14}$. Silica fume is high reactive and extreme fine material, it strengthens Interfacial Transition Zone of concrete. Most of the researchers found that in addition to fly ash when silica fume added to concrete it provides significant amount of CSH at early ages.

\subsubsection{Ground Granulated Blast Furnace Slag}

It is a by-product obtained in iron manufacture in blast furnace heated iron ore, lime stone, and coke between 1400 to $1600{ }^{0} \mathrm{C}$, molten slag quenched by water into fine granulated slag it composed of calcium-alumino silicates of glassy shape. Partial replacement of GGBS to cement in 
concrete, it makes concrete more durable than conventional concrete but it may slower the initial hydration compared to conventional concrete because of denseness of cement paste. Workability of concrete also becomes good even up to $50 \%$ GGBS replacement level with various w/c ratios.

\subsubsection{Metakaolin}

It is obtained by heating of Kaolin to 650 to $900{ }^{\circ} \mathrm{C}$ followed by grinding to achieve finer material. It composed of reactive silica, alkalies, carbon, sulphur compounds. In harden state it reduce the porosity. It reacts with calcium hydroxide and form $\mathrm{CSH}$, it is most required in strength development phase. It gives denseness to concrete due to high fineness yields to lower permeability. Compared SF blended concrete, it gives lower porosity and finer pore size distribution. It also effect the setting time of concrete.

\section{BINARY BLENDED CONCRETE}

\subsection{Properties of Fresh Concrete}

Effect of water-to- binder ratio on binary blended concrete using class $\mathrm{F} \&$ Class $\mathrm{C}$ fly ash, Slag used as replacement to cement $15 \%, 30 \%$ of fly ash of different class and $20 \%, 40 \%$ of slag was replaced with $0.4,0.45$ water to binder ratio. A fixed cementitious content of $356 \mathrm{~kg} / \mathrm{m}^{3}$ was used for all mixtures; the ratio of $\mathrm{FA}$ to $\mathrm{TA}$ was selected as 0.42 According to ASTM C143 workability was investigated. For a fixed w/b ratio, an increase of dosage of class $F$ fly ash, the workability increased because class $\mathrm{F}$ fly ash particles reduces the inter particle friction in concrete mixtures there by improvement in workability (Kosmatka et.al 2008).The highest slump was obtained by binary mixture having 15 and $30 \%$ of class F fly ash ${ }^{(1)}$.

Silica fume was used as replacement to cement with a variable of $2.5 \%$ up to $10 \%$ with a w/b ratio 0.38 with a cement content of $420 \mathrm{~kg} / \mathrm{m}^{3}$. The use of silica fume has resulted increased water demand than the control mix ${ }^{(2)}$.

When replacing cement with GGBS, water demand was increased in the mix design as increasing with GGBS content is due to higher specific surface of GGBS particle. For a constant workability, water requirement is less compared to control mixture as GGBS content increase ${ }^{3}$, GGBS added partial replacement of $0,15,30,50,70$ and $90 \%$ by weight.

When replacing with metakaolin in concrete, it presence reducing the workability and also setting time' and it requires more super plasticiser compared to control mixtures. Due to high fineness of Metakaolin, addition of super plasticiser to concrete with addition of metakaolin can keep the workability as constant with increasing the metakaolin replacement to cement in concrete .Al-Akhras N.M ${ }^{4}$ studies reported that the workability of concrete with metakaolin with 5,10 and $15 \%$ replacement to cement with w/b ratio of 0.5 and 0.6 , slump was ranging from $70-90 \mathrm{~mm}$ when the super plasticiser dosage increases with metakaolin dosage.

\subsection{Compressive Strength}

Strength development of the concrete replacing with fly ash, the compressive strength of the concrete with $50 \%$ fly ash replacement is low. With 0.6 water-binder ratio, at 28 days the strength of fly ash concrete is $59 \%$ of Portland cement concrete, at 90 days it was $75 \%$, which shows the significant strength development rate of fly ash concrete between 28 and 90 days. With water-binder ratio 0.38 , the strength of fly ash concrete is about $85 \%$ at 28 and 90 days. Comparing these two, fly ash is more effective at low water-binder ratio ${ }^{(5)}$.At lower water binder ratios, fly ash contributes developing strength of concrete by the filling effect of pores and by enhancing the cement hydration, in long term compressive strength has found to increase up to $30 \%$ of FA replacement level ${ }^{(6)}$.

According to different studies made on GGBS replacement to cement, early age strengths values of GGBS concrete are lower than the control mixtures. As the curing process is in progress, the GGBS concrete has showed more strength values than control mixtures. Strength gains takes longer time in GGBS blended concrete due to pozzolanic reaction is slow and depends on the Calcium hydroxide availability and as increase in GGBS content strength gain increase in time. The optimum level of GGBS content to get the maximized compressive strength is at about $55-59 \%$ of the total binder content $^{(3)}$.

Compressive strength of concrete containing silica fume are higher than control concrete mixtures at all ages and increased with increase in dosage of silica fume because silica fume is much finer compared to other SCM .As a result of higher surface area, the pozzolanic reaction proceeds rapidly and strength quickly developed ${ }^{(2)}$.

\subsection{Durability Properties}

Penetration of aggressive substance into concrete via micro cracks or pores it leads to deterioration of concrete due to this, it reduce useful service life of structures. This type of deterioration may takes place due to sulphate attack, chloride penetration, alkali-silica reaction .It can be reduced by adding the Supplementary Cementitous Materials (SCMs).These SCM's reduce the pores in concrete as well as increase its density.

Many researchers studied durability of concrete by incorporating the SCM's like Fly ash, GGBS, Silica fume with different test procedures most of them was evaluated using RCPT, because it gives good evaluation within short duration. Some of the papers reviewed and summarised as follows.

M.Sharfuddin et. $\mathbf{a l}^{7}$ replaced cement with fly ash and GGBS in three levels $(25,50$ and $75 \%)$ and also incorporated silica fume $10 \%$,conducted RCPT after 7 days curing. The charge passed in control specimen was 2813 coulombs, charged passed in fly ash concrete 3323, 3926 and 6157 coulombs and GGBS incorporated concrete 1929, 1368 and 1727 coulombs. Where as in silica fume incorporated 
concrete was 1092 coulombs. Silica fume and GGBS concrete exhibits lower electrical charge passed compared to control concrete .Fly ash concrete exhibits higher electrical charge passed compare to all other specimens irrespective of level of replacement. It is clearly indicated that the high volume fly ash concrete more permeable compare to other specimens, it's due to the combine effect of high porosity and lower relative amount of pozzolanic products. In this study observed that only $9 \%$ reduction in the $25 \%$ slag replacement compared to the plain concrete, whereas fly ash concrete there is no reduction in the charge passed.

Murthi et.al ${ }^{8}$ investigated acid resistance of concrete of fly ash replacement to cement of different grades of concrete (M20, M30 and M40) with a replacement level of 20\%. Acid resistance assessed using mass loss by immersing cubes in acid solutions $\left(\mathrm{H}_{2} \mathrm{So}_{4}\right.$ and $\left.\mathrm{Hcl}\right)$ and Strength Deterioration Factor of cubes expressed in percentage. Control specimens of all grades were severely deteriorated after immersing in solutions up to 32 weeks. Fly ash concrete was exhibited only $10 \%$ of mass loss immersed up to 32 weeks, whereas control specimens were loosed mass up to $19.6 \%$. When compared to SDF values, Control specimens were more than $78 \%$.

Kyong Yun Yeau et.al ${ }^{9}$ presented experimental results of chloride permeability of concrete was evaluated using two types of cement (Type I and Type V ) and replaced with GGBS $(25 \%, 40 \%$ and $55 \%)$. The premature deterioration of concrete structure caused due to mainly penetration of chloride .RCPT results were showed that permeability of chloride ions into GGBS concrete specimens reduced as period of curing or with increased amount of GGBS by binder weight. Type $\mathrm{V}$ cements was more permeable than Type I cement. When increasing volume of GGBS, chloride ion concentration of type $\mathrm{V}$ cement was higher than of type I cement.

According to Sengul $\mathrm{O}^{10}$ research, incorporated silica fume improves the bond of cement matrix and sand and it will enhance the freeze thaw resistance .Against chloride diffusivity, the concrete contain silica fume gives better performance because of improved pore structure of cement paste and densification of aggregate -cement paste interface.

Ali Reza Bagheri ${ }^{2}$ incorporated silica fume in concrete with various dosages $(2.5,5,7.5$ and $10 \%)$ conducted RCPT ,results showed that there is reduction in charge passed at all ages due to incorporation of silica fume and the reduction increased for higher dosage of silica fume. when slag replacement in the concrete with a dosage of 15,30 and 50\% ,the results showed that with increasing slag content the resistance to chloride penetration is improved due it's filling of pores and effect on microstructure of paste.

\section{TERNARY BLENDED CONCRETE}

Different Properties of concrete were improved with addition of SCM's .Incorporating of high volume of single type of SCM may have negative impacts on concrete properties like
1. Silica fume tends $t$ increase the water requirement owing to its small particles size .Silica fume cost is so high and its workability is low as compared to fly ash or GGBS.

2. Replacing metakaolin in concrete reduces the workability and setting time.

3. The incorporation of $50 \%$ slag need ensure adequate protection against Alkali-silica Reaction may lead to poor resistance to de-icer salt scaling ${ }^{13}$.

4. Drawback of Fly ash addition to concrete is the reduction of initial age strength development rate and setting time increment ${ }^{8}$.

To overcome these drawbacks, researchers explored the incorporation of more than one type of SCM's in concrete.

The use of appropriately proportioned ternary blends allows the effects of one SCM to compensate for the inherent shortcomings of another. For example, the additions of silica fume to slag concrete can prevent the excessive bleeding problems ${ }^{13}$.

Many researchers used silica fume in ternary concrete in addition to fly ash/Slag because it gives considerable improvement in durability properties and mechanical properties but the cost is so high, limited availability and silica fume alone having a drawback of more water demand with a dosage of higher than $5 \%{ }^{11}$. When slag incorporation in concrete gives a relatively low water demand, combining silica fume with slag in binary mixes can overcome the high water demand.

Ali Reza Bagheri ${ }^{2}$ investigated mechanical and durability properties of ternary concrete by combining silica fume and low blast furnace reactive slag with different mix proportions. As stated in binary blended concrete ,the strength reduction in slag concrete and higher water demand in silica fume concrete was improved in ternary mix of slag and silica fume blended concrete with $15 \%$ slag and dosage of $2.5,5,7.5$ and $10 \%$ of silica fume. Whereas $30 \%$ slag mixes strength properties still have lower values compared to control mixes. For ternary mixes containing $50 \%$ slag much lower than control mixes. It is due to the complete filling of pores in concrete with high volume of slag and affect the pozzolanic action of silica fume has not able to compensate the reduced slag activity caused by lower alkalinity.

By the use of ternary mixes, 28 day durability properties of slag based blended concrete was increased compare to the conventional concrete with addition of silica fume. Charge passed through the specimens affected by the microstructure of paste and chemical composition of pore solution. Durability has much more affect than the strength due to effect of pore connectivity. In this study they used only low reactivity slag. Similar results were observed in Roland Bleszynski et.al ${ }^{12}$ researches, they concluded from the various tests in outdoor and laboratory exposure conditions that ternary mix containing Silica Fume and Blast Furnace Slag offers increased resistance to Alkali Silica Reaction expansion, ingress of chloride ions salt scaling. Optimum results were obtained with $0.3 \mathrm{w} / \mathrm{b}$ ratio $5 \%$ of GGBS added to the $10 \%$ SF specimens in curing period of 120days in lime saturated water. 
To overcome the drawback of fly ash replacement to cement in concrete by adding super finer material admixture like silica fume addition to fly ash. Addition of Silica fume increase the early age performance and Fly ash improves the harden concrete properties continuously ${ }^{13}$.

Alaa M.Rashad et.al ${ }^{14}$ investigated on ternary blended concrete consisting of fly ash and silica fume with various replacement levels (FA 60\%, SF 10\% and FA 50\%, SF20\%), binary mix of $70 \%$ of FA level and control concrete (CC). when compared these mixture like CC vs FA60SF10 vs FA70 and FA50SF20 vs CC vs FA 70, when the $70 \%$ replacement of fly ash alone the compressive strength was reduced at all ages, the highest reduction was at 7 days of hydration. When incorporation of SF $10 \%$ with the $60 \%$ FA, the compressive strength was increased remarkably at all ages $5.8 \%$ at 7 days and $40 \%$ at 28 days related $70 \%$ of FA replacement. Increasing the SF level to $20 \%$ from $10 \%$ with combination of $50 \%$ FA further increment in compressive strength at all ages.

P.Murthi et.al ${ }^{8}$ investigated on acid resistance of ternary mixture containing silica fume and fly ash and compared with the binary mixture containing fly ash and control specimens Acid resistance evaluated by mass loss and strength deterioration factor when specimens were immersed in acid solutions. Ternary mixtures were less affected than that off binary and control specimens immersed in $5 \% \mathrm{H}_{2} \mathrm{So}_{4}$. Silica fume affect the early ages resistance against permeability and fly ash affect the latter age's permeability by preventing the entry of solution into concrete.

Addition of silica fume may increase the early age strength in the ternary mixture but these substances are generally alkaline in nature which may lead to alkali-silica reaction $^{21}$.Silica fume alone may affect the early age properties, some studies showed that it may not affect the early age properties of High volume fly ash -high strength concrete $^{15}$.

Gengying $\mathrm{Li}^{16}$ made an effort to study the influence combination of $25 \%$ FA and $15 \%$ GGBS (ternary)on the strength development, by comparing the $40 \%$ FA replaced concrete(binary) and Control specimen. Binary mixture exhibited highest strength at the end stage among three but its strength was lowest before 56 days. Whereas ternary mixture had slightly lower values compared to control specimens and maintain the high long term strength. In durability aspects, the evaluation made weight loss and strength reduction due to immersing specimens in $\mathrm{H}_{2} \mathrm{So}_{4}$ solution. Relative strength of ternary mix (strength ratio specimens immersed in acid solution to the specimens immersed in water) decreasing rate was low compared to binary mix and control specimens. Weight loss is below $8 \%$ for ternary mix exposed 50 weeks period, it is very less loss compared to the control and binary mixes.

Zongjin Li et.al ${ }^{17}$ investigated the mechanical properties of concrete with the admixture combination of metakaolin $(10 \%)$ and slag (dosage of 20 or $30 \%$ ). This combination was effected usage of super plasticizers in concrete, and also enhanced fluidity of paste, 28 days compressive strength.

\section{QUATERNARY BLENDED CONCRETE}

Quaternary blended concrete is also called as Green High Performance Concrete, because cement was replacing to maximum level with improving the properties better than binary and ternary blended concrete.

Yunsheng Zhang et.al ${ }^{19}$ studied reduction of heat in hydration and reduction of super plasticizer usage with a combination of FA, SF and slag .By adding these mixture reduction in 3day heat of hydration. Wei Sun et.al ${ }^{18}$ investigated corrosion properties of quaternary blended concrete containing FA, SF and Slag silica fume incorporation with fly ash or in quaternary mixture gives higher resistance to steel corrosion.

According to Yanzhou Peng et.al ${ }^{20}$ optimum usage of FA, slag and SF are $10 \%, 17 \%$ and $15 \%$ by weight respectively.

\section{CONCLUSION}

Based on review of the different researches on blended concretes, conclusions as follows:

1. The addition of SCM's in concrete to enhance the properties of conventional concrete and decreasing the cement content so that it can reduce the harm to environment. 2.By addition of single type of SCM may improve the some properties of concrete based on SCM characteristics it may affect the other properties like early age properties , resistance to penetration of aggressive substance, setting time and workability etc.

3. Multi blended concretes like ternary and quaternary to counteract the drawbacks of binary blended concretes.

4. Still more research is required to study the behaviour of multi blended concretes to enhance the optimum usage of supplementary cementitious materials.

\section{REFERENCES}

[1] Ezgi Yurdakul ,Peter C.Taylor,Halil Ceylan and Faith Bektas "Effect of Water to Binder ratio, Air Content and type of cementitious on Fresh and Hardened Properties of Binary and Ternary Blended Concrete" ASCE J mater Civil Engineering 04014002 page no $1-11,2014$

[2] Ali Reza Bagheri,Hamed Zanganesh,Mohamad Mehdi Moalemi "Mechanical and durability properties of ternary concretes containing silica fume and low reactivity blast furnace slag" cement and concrete composites 34(2012) page no 663-670.

[3] A.Oner,S Akyuz "An Experimental Study on optimum usage of GGBS for the compressive strength of concrete." Cement and Concrete Composites 29(2007) page no 505-514.

[4] Al Akhras N.M, Durability of metakaolin concrete to sulfate attack Cement and Concrete Research 2006 vol 36 pp no.1727-1734. 
[5] Ozkan Senguland Mehmet Ali Tasdemir "Compressive strength and Rapid chloride permeability of concrete with Ground Flyash and slag" Journal of Materials in Civil Engineering ASCE September 2009:21: 494-501.

[6] Peon C.S ,Kou S.C,Lam.l "Compressive strength , chloride diffusivity and pore structure of high performance metakaolin and silica fume concrete "Construction and building materials 2006,Vol 20,PP no $858-865$,

[7] Msharfuddin Ahmed, Obada kayali and Wendy Anderson "Evaluation of Binary and Ternary Blends of Pozzolanic Materials using RCPT" Journal of Materials in Civil Engineering ASCE September 2009 :21: 446-453

[8] P.Murthi and V.Siva Kumar "Studies on Acid Resistance of Ternary Blended Concrete" Asian Journal of Civil Engineering (BUilding and Housing) Vol9, N05 2008 Page no-473-486.

[9] Kyong yun yeau,Eun kyum kim,"An Experimental study on corrosion resistance of concrete with GGBS " Cement and Concrete Research 35(2005) 13911399.

[10] Sengul O, "Effects of pozzolanic materials on mechanical properties and chloride diffusivity of concrete ".

[11] Voglis N, Kakali g, Chaniotakis E,Tsivilis S "Portland cements, their properties and hydration compared to those of other composite cements " cement and concrete composites 27(2) 2005 191-6.

[12] Roland Bleszynski, R Doug Hooton, Michael D.A.Thomas, and Chris A.Rogers "Durability of ternary blended concrete with silica fume and blast furnace slag: Laboratory and outdoor exposure site studies" ACI Material Journal Sept-Oct 2002, Title No 99-M51 page no 499-508.

[13] Bouzuobba Nabili "Development of Ternary Blends for High Performance Concrete" ACI Material Journal No.1 101(2004)19-29.

[14] Alaa M. Rashad ,Hosam El-Din H., Seleem and Amr F.Shaheen ,"Effect of silica fume and slag on compressive strength and abrasion resistance of HVFA concrete." , International journals of Concrete structures and materials, Vol 8, No.1 pp 69-81 march 2014.

[15] Giaccia GM ,Malhotra VM," Concrete incorporating high volumes of ASTM class F flyash ",ASTM cement concrete aggregates 1988;10:88-95.

[16] Gengying Li,Xiaohua Zhao " Properties of concrete incorporating flyash and GGBS" Cement and Concrete Composites 25(2003)292-299.

[17] Zongjin Li ,Zhu Ding ,Property improvement of portland cement by incorporating metakaolin and slag" ,Cement and Concrete Research 33,2003,pp 579-584.

[18] Wei Sun ,Yunsheng Zhang ,Sifeng Liu ,Yanmeu Zhang, "The Influence of mineral admixture on resistance to corrosion of steel bars in GHPC" Cement and concrete research,34:2004,pp no 1781 -1785.
[19] Yunsheng Zhang, Wei Sun, Sifeng Liu "Study on the Hydration of heat binder paste in High Performance Concrete", Cement and concrete research, 32:2002, pp no 1483-1488.

[20] Yanzhou Penga ,Shugunag Hub , Quingjun Ding, "Dense packing properties of mineral admixtures in cemetitious material Paricuology 7,2009,pp no 399402.

[21] Aiqin W,Chengzhi Zh , Mingshu T , Ninsheng Zh , "ASR in mortar bar containing silica glass in combination with high alkali and high fly ash contents", cement concrete composite 1999,375-382. 